\title{
Impact of Drying and Wetting Cycles on Vegetation Cement-soil Physical and Mechanical Properties
}

\author{
Xudong Hu*(**), Jiazhen Gao*(**), Mingtao Zhou*(**)†, Songtao Peng***, Wennian Xu*(**) \\ and Chenyuan Wang** \\ *Hubei Key Laboratory of Disaster Prevention and Mitigation, College of Civil Engineering and Architecture, China \\ Three Gorges University, Yichang, 443002, China \\ **College of Civil Engineering \& Architecture, China Three Gorges University, Hubei Yichang, 443002, China \\ ***Dagu Hydropower Branch, Huadian Tibetan Energy Co., Ltd., Tibet Shannan 856200, China \\ $\dagger$ Corresponding author: Mingtao Zhou; zmt@ @ctgu.edu.cn
}

Nat. Env. \& Poll. Tech.

Website: www.neptjournal.com

Received: 05-11-2020

Revised: 15-12-2020

Accepted: 22-01-2021

Key Words:

Vegetation cement-soil

Drying-wetting cycles

Crack

Initial water content

\begin{abstract}
The physical and mechanical properties of the ecological slope protection substrate will be affected by long-term variation of the meteorological condition, resulting in the stability of the substrate being reduced. So an artificial substrate of vegetation cement-soil was selected as the research object to prepare specimens with the different initial moisture content of $13 \%, 19 \%, 25 \%, 31 \%, 37 \%$, and $43 \%$. And a series of tests are conducted to investigate the evolution of the physical and mechanical properties under drying-wetting cycling conditions. Typical results of the vegetation cement-soil evolution can be divided into three stages: cement hydration stage, shrinkage stage, and stabilization stage. In terms of different initial moisture content, the shrinkage cracks number, cracks length, crack width, and cracks surface area are increased first and then stabilize with the increase of the number of drying-wetting cycles. In contrast, the cohesion and internal friction angle of the vegetation cement-soil is reduced with the increase of the number of cycles. Comprehensive analysis shows that the initial moisture content of vegetation cement soil ranges from $25 \%$ to $31 \%$ is the optimal choice to ensure substrate stability in production practice.
\end{abstract}

\section{INTRODUCTION}

Vegetation cement-soil is an artificial substrate prepared from soil, cement, organic material, a special additive named Runzhi (a patent invented by China Three Gorges University), water, in a certain proportion for cut slope revegetation. The patent and related research clearly indicate the optimal mass proportioning of vegetation cement-soil is 100 (soil): 6 (cement): 6 (organic material): 3 (Runzhi additive) (Xu et al. 2012). As a result, the artificial substrate has both physical and mechanical properties of soil and cement, such as scour resistance, stability, expansion, and contraction (Xu et al. 2012). The vegetation cement-soil has been widely applied on various cut slopes revegetation in southern China (Liu et al. 2012, Zhao 2018) which are often subjected to alternating mega temperature and rainstorm weather changes. In such a case, the physical and mechanical properties of the vegetation cement soil are inevitably influenced by the drying-wetting process.

Alternate drying-wetting cycle (DWC) are recognized as important factors that can affect the soil's physical and mechanical properties (Kuwano et al. 2011, Rao \&
Revanasiddappa 2006), and reshape the cement stability as well (Suddeepong et al. 2018). For example, the expansive soil shows significant swelling or shrinkage characteristics when the soil gains or loses water, respectively, and cracks gradually develop as the number of DWC increases (Ye et al. 2018). Due to the difference in the content of organic matter, and mineralogy, the cracks of clay soil show a denser crack pattern with a smaller aperture under the repeated drying-wetting cycles (Diel et al. 2019, Wang et al. 2016). In addition to the abovementioned characteristics, the soil strength reduces significantly during the drying-wetting process. However, the strength of cement-soil shows an increase first, then a decreasing trend when the number of DWC increases, and it changes with different water content (Zhang et al. 2014, Zhang 2018). As an artificial composite ecological restoration substrate, the physical and mechanical properties of vegetation cement soil are different from the soil and cement. Moreover, limited works of literature consider the influence of initial moisture content on the soil and cement physical and mechanical properties during the drying-wetting process. 
The effect of initial moisture content on the strength of cement is obvious (Zhang et al. 2014), especially in cement soil. Hence, the initial moisture content is selected as a variable in this paper, and the distribution of cracks is considered. Laboratory simulation tests of drying-wetting cycles are conducted to measure the swelling, shrinkage, and crack development. The binary image processing technology is used to quantitatively analyze the development of cracks. Moreover, the direct shear test is carried out to determine its shear strength after several times of drying-wetting cycles. Finally, the optimal initial moisture content could be obtained by the method of comparative analysis.

\section{MATERIALS AND METHODS}

Materials Source: The materials include soil, cement, organic matter, Runzhi additive, and water. The yellow-brown soil was selected according to its physical properties (Table 1). The yellow-brown soil was collected from the botanical garden of China Three Gorges University and passed through sieves of $2 \mathrm{~mm}$ mesh size. P.O 32.5 ordinary Portland cement, with a dry density of $3.10 \times 10^{-3} \mathrm{~g} . \mathrm{mm}^{-3}$, was purchased from Yichang Huaxin Cement Factory. Sawdust of Metasequoia glyptostroboides was adopted as organic matter produced from Yichang Yemingzhu Saw Mill. The Runzhi additive, including mineral powder, water-retaining agent, and complex fertilizer, shows weak acidity that can neutralize the basicity of the cement in the vegetation cement-soil.

Referring to the weak expansive soil sharply influenced depth by climate is mainly $1.6 \sim 2.3 \mathrm{~cm}$ in southern China (Xiang \& Dong 2012), and the size of repeated ring specimens was intended to be $\Phi 61.8 \mathrm{~mm} \times 20 \mathrm{~mm}$. The preparation of the specimen complied with the National Standard for Soil Test Method (GB/T 50123-2019), and the proportion was 100 (soil): 6 (cement): 6 (organic material): 3 (Runzhi additive). The minimum and saturated moisture contents of vegetation cement soil were 13\%, 43\%, respectively (Xu et al. 2012). Therefore, we made three groups (Group A, Group B, Group C) of specimens with 6 different initial moisture content at $5 \%$ intervals, which were $13 \%, 19 \%, 25 \%, 31 \%, 37 \%$, and $43 \%$, respectively. The prepared specimens of Group A were taken for the free swelling test directly without curing, but the Groups B and C were maintained under standard curing conditions (temperature $20^{\circ} \mathrm{C}$ and relative humidity 95\%) for 7 days. One group (Group A) was a control specimen, Groups $\mathrm{B}$ and $\mathrm{C}$ were used to conduct the drying-wetting cycles test, and Group $\mathrm{C}$ would take a direct shear test after each drying-wetting cycle test. Moreover, the mineral composition of the vegetation cement-soil specimen can be seen in Table 2 according to the X-ray analysis.

Test Method and Equipment: When the curing was finished, the specimens of Groups B and C were taken out to perform the drying-wetting cycling tests. In the drying process, the specimens were placed in an oven (DHG$9035 \mathrm{~A}$ ) with a temperature of $40 \pm 1^{\circ} \mathrm{C}$ for $24 \mathrm{~h}$. In order to obtain the evolution of cracks after the drying process, an HD digital camera was used to take a photograph of the top surface of the specimen, and the distance between camera and specimen was always equivalent. In the subsequent wetting process, a GDB-1 type stacked saturator was used to wetting the specimens. Referring to the drying-wetting cycles of residual soils conducted by Kong et al. (2009), the number of our drying-wetting cycles was set to 8 times, and each specimen should be taken out to measure the expansion and contraction after the drying-wetting cycles. Group A was placed at laboratory conditions (temperature $20^{\circ} \mathrm{C}$ and relative humidity 95\%) during the free swelling test. Each specimen in Group A was wrapped with plastic film to let them expand and contract freely. The WZ-2 dilatometer was used to measure the expansion and contraction every 2h same as the Group B.

Each initial moisture content specimen in Group $\mathrm{C}$ has been made to six parallel samples divided into Group C-1, Group C-2, Group C-3, Group C-4, Group C-5, Group C-6. The number of C- 1 to C- 6 represents the times of drying and wetting cycles test. For example, Group C-1 only conducted one cycle test of drying and wetting. Moreover, the drying-wetting cycling tests of Group C and Group B were conducted at the same time. When the drying-wetting cycling tests were finished, the ZJ Quadruplex Strain Controlled Direct Shear Apparatus was used to conduct the direct shear tests.

Table 1: Physical properties of yellow-brown soil.

\begin{tabular}{|llllllll|}
\hline Specific gravity & $\begin{array}{l}\text { Density } \\
\text { g.cm }{ }^{-3}\end{array}$ & $\begin{array}{l}\text { Natural moisture } \\
\text { content } \omega / \%\end{array}$ & $\begin{array}{l}\text { Porosity } \\
/ \%\end{array}$ & $\begin{array}{l}\text { Liquid limit } \\
\omega \mathrm{L} / \%\end{array}$ & $\begin{array}{l}\text { Plastic limit } \\
\omega \mathrm{P} / \%\end{array}$ & $\begin{array}{l}\text { Plasticity } \\
\text { index IP }(\%)\end{array}$ & $\begin{array}{l}\text { Liquidity } \\
\text { index IL }(\%)\end{array}$ \\
\hline 2.58 & 1.79 & 16.3 & 40.18 & 31.7 & 16.9 & 1.1 \\
\hline
\end{tabular}

Table 2: Mineral composition of the specimens.

\begin{tabular}{|lllllll|}
\hline Composition & Quartz $/ \mathrm{SiO}_{2}$ & Albite $/ \mathrm{Na}_{2} \mathrm{O} \cdot \mathrm{Al}_{2} \mathrm{O}_{3} \cdot 6 \mathrm{SiO}_{2}$ & Illite & Calcite/CaCO & Montmorillonite & Dolomite \\
\hline Mass fraction/\% & 56 & 14 & 10 & 9 & 8 & 3 \\
\hline
\end{tabular}


Data Processing Method: First, Photoshop software was used to correct the images and convert them into grayscale images. Then, Matlab software was used to binarize the images and remove the miscellaneous points. A threshold was set to turn the crack areas into black and the other areas into white. Finally, the contour and centerline vectors were also carried out by Matlab software to estimate the cracks area, width, and length. According to the geometric characteristics of cracks on the surface of the specimens, four indicators were used for quantitatively analyzing the generation of the cracks (Chu 2015, Li et al. 2014). The calculation formulas are as follows:

$$
\begin{gathered}
\delta_{a}=\frac{\sum_{i=1}^{n_{i}} A_{i}}{A} \\
\delta_{b}=\frac{\sum_{i=1}^{n_{i}} l_{i}}{A} \\
\delta_{c}=\frac{\bar{l}}{\bar{d}} \\
\delta_{d}=\frac{A_{0}-A}{A} \times 100 \%
\end{gathered}
$$

Where, $\mathrm{i}$ is the number of cracks in the survey; $\mathrm{A}_{i}$ represents the crack area, $\mathrm{mm}^{2}$; $\mathrm{A}$ is the surface area of the specimen, $\mathrm{mm}^{2} ; 1_{i}$ represents the crack length, $\mathrm{mm} ; \bar{l}$ represents the average length of the crack, mm; $\bar{d}$ represents the average interval of crack, $\mathrm{mm}^{2} ; \mathrm{d}_{\mathrm{a}}, \mathrm{d}_{\mathrm{b}}, \mathrm{d}_{\mathrm{c}}$, and $\mathrm{d}_{\mathrm{d}}$ represents the crack area ratio, length ratio, width ratio, and surface shrinkage ratio, respectively; $\mathrm{A}_{0}$ represents the initial surface area of the specimen, which is equal to $3000 \mathrm{~mm}^{2}$.

\section{RESULTS AND DISCUSSION}

Free and Cyclic Swelling-Shrinkage: The evolutions of control Group A under laboratory conditions is shown in Fig. 1. As shown in Fig. 1, for the specimens with a curing time of nearly $180 \mathrm{~h}$, the shrinkage of the vegetation cement soil can be divided into three stages. Initially, the specimens, with different initial moisture content, were sharply shrunk due to the hydration reaction between cement and water within 2 hours, and the maximum shrinkage reached 0.4 $\mathrm{mm}$. After the cement hydration stage, the shrinkage of the specimens showed a linear increase and entered the stage of shrinkage. The increasing rates of $13 \%, 19 \%, 25 \%, 31 \%$, $37 \%$, and $43 \%$ initial moisture content specimens were 0.017 , $0.014,0.013,0.012,0.013$, and 0.019 , respectively. The initial moisture content of $43 \%$ specimen in the period of shrinkage was the longest (nearly $110 \mathrm{~h}$ ) among them, and the shortest $(80 \mathrm{~h})$ was the specimen with $13 \%$ initial moisture content. Finally, the shrinkage of vegetation cement-soil gradually stopped under laboratory conditions, showing a stabilization stage.

After each time of the drying-wetting cycle, the shrinkage would be measured to calculate the swelling-shrinkage rate (Fig. 2). The shrinkage rate was increased as a power func-

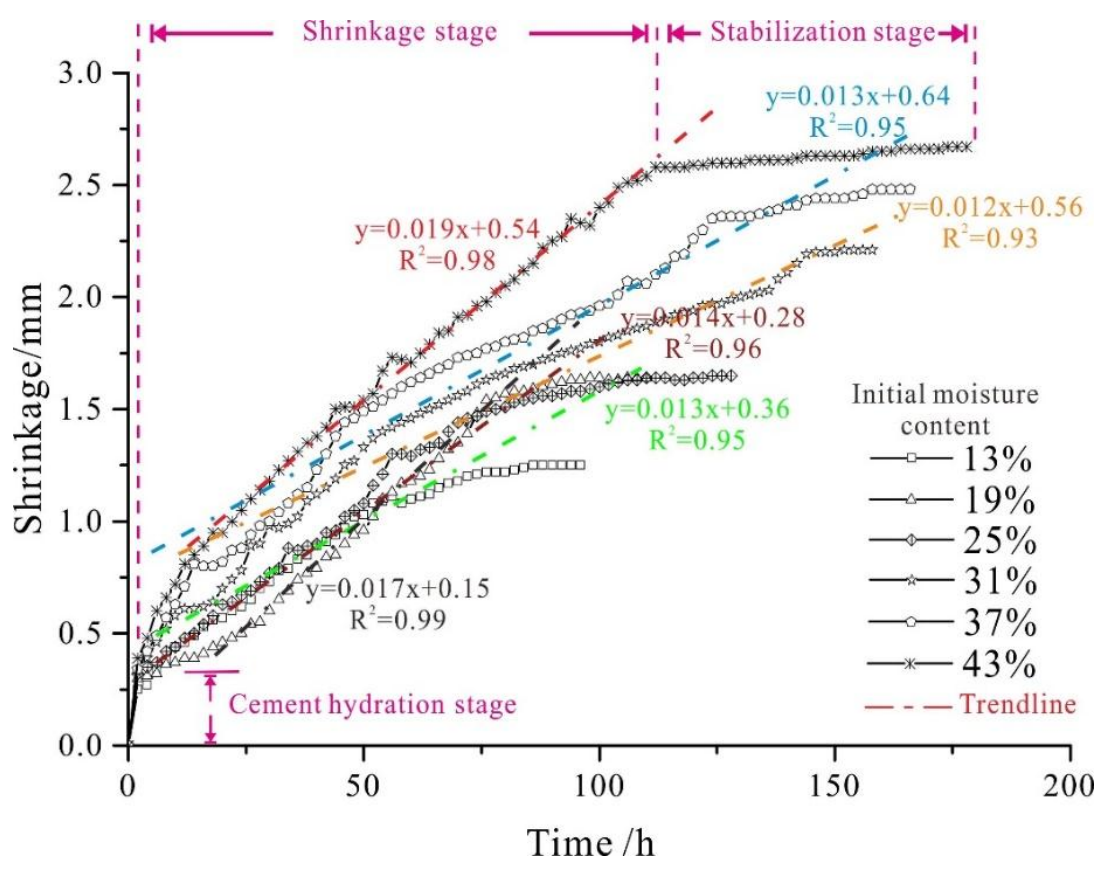

Fig. 1: Free shrinkage time course curve of the control specimens (Group A) under laboratory conditions. 


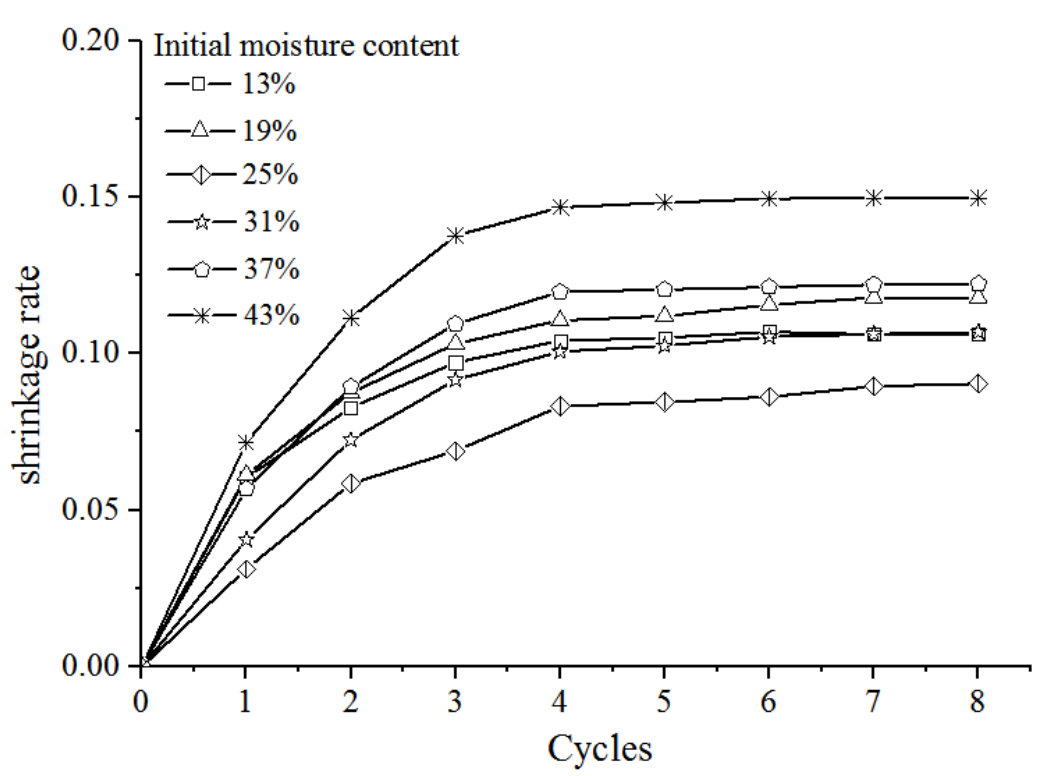

Fig. 2: Cyclic shrinkage rate of Group B during the drying-wetting cycles.

tion with the increase of the cycles. Moreover, the shrinkage rates of each initial moisture content were tiny, indicating the vegetation cement-soil has the effect of restoring itself to its original state after shrinking or expanding. In terms of different initial moisture content, the shrinkage of the specimen with an initial moisture content of $25 \%$ was the smallest with 0.08 , and the specimen with an initial moisture content of $43 \%$ is the largest with 0.15 . Moreover, it can be found that the shrinkage rates of each specimen were becoming steady after the 4th cycle. Compared to the control Group A under laboratory conditions, the shrinkage of different initial moisture content in Group B was larger than that in Group A.

Distribution of Surface Cracks: The binary image of specimen cracks evolution after drying and wetting cycles is shown in Table 3. Group A, which was placed in the laboratory condition without experiencing the drying and

Table 3: Binary image of cracks after drying and wetting cycles.

\begin{tabular}{|c|c|c|c|c|c|c|}
\hline Initial moisture content & $13 \%$ & $19 \%$ & $25 \%$ & $31 \%$ & $37 \%$ & $43 \%$ \\
\hline $\begin{array}{l}\text { Group A } \\
\mathrm{N}=0\end{array}$ & & & & & & \\
\hline Group B N=3 & & & & & & \\
\hline Group B $N=4,5, \ldots 8$ & & & & & & \\
\hline
\end{tabular}

Note: $\mathrm{N}$ represents the number of drying and wetting cycles 
wetting cycles, has no obvious cracks. After 3 times of drying and wetting cycles, the cracks gradually emerged except for $13 \%$ initial moisture content. The length, width, and area of the cracks started to appear and the cracks increasing rate rose with the increase of the drying-wetting cycles. $13 \%$ and $43 \%$ initial moisture content specimens were on the edge of disintegration after 5 to 8 cycles of drying-wetting, especially the $13 \%$ initial moisture content specimen because of the lowest initial moisture content leading to the specimen become loose. $19 \%$ and $37 \%$ initial moisture content specimens were only divided into several small pieces by cracks, and a large number of cracks were also produced, but the integrity was not destroyed. $25 \%$ and $31 \%$ initial moisture content specimens saved a complete structure with only a few cracks and performed best among them. Therefore, when the slope ecological restoration project is implemented, the initial moisture content of the vegetation cement soil should be controlled between $25 \%$ and $31 \%$ to enhance the stability of the project.

The characteristic parameters of average crack width, area ratio, length ratio, and surface area shrinkage were increased with the increase of the number of drying and wetting cycles in Fig. 3a, b, c, d, and stabilized after the 4th cycle. The highest average crack width after 5 to 8 drying and wetting cycles was the specimen with $13 \%$ initial moisture content, and the value reached $0.26 \mathrm{~cm}$. In the contrast, the smallest was the $25 \%$ initial moisture content with the peak width of $0.15 \mathrm{~cm}$, followed by the $31 \%$ initial moisture content with a peak width of $0.16 \mathrm{~cm}$ (Fig. 3a). And the stable area ratio of each specimen was $8.3 \%, 5.6 \%, 2.9 \%, 4.5 \%$, $5.1 \%$, and $7.2 \%$, respectively (Fig. $3 b$ ). The evolution of crack width was consistent with crack area, and the adhesive force of $25 \%$ and $31 \%$ initial moisture content specimens were performed best.

The peak value of length ratio was $0.31,0.26,0.19,0.20$, 0.23 , and 0.29 , respectively (Fig. 3c). The largest one is a $13 \%$ initial moisture content specimen, and the smallest one is a $25 \%$ initial moisture content specimen. The length ratio results implied that the vegetation cement-soil with $19 \%$ initial moisture content performed worst, but the one with $25 \%$ initial moisture content was the best. Moreover, it can be seen from Fig. 3d that the surface shrinkage of the specimens with an initial moisture content of $13 \%$ and $43 \%$ was significantly higher than that of other specimens. Comprehensively, the crack evolution of vegetation cement-soil with an initial moisture content of $25 \%$ or $31 \%$ was the lowest compared to others, which proved once again that the vegetation cement-soil with the initial moisture content between $25 \%$ and $31 \%$ had high stability.

Post-Cyclic Shear Strength: Results of the direct shear tests conducted on Group C-1, C-2, C-3, C-4, C-5, and C-6 are given in Fig. 4a, b. The cohesive force and internal friction angle were reduced with the increase of the drying-wetting cycle. After 4 cycles, the reduction trend of the cohesive force and internal friction gradually slows down. Without the drying-wetting cycle, the cohesive force of each initial moisture content specimen ranges from $42 \mathrm{kPa}$ to $53 \mathrm{kPa}$ (Fig. 4a). The internal friction angle of each specimen was distributed from $27^{\circ}$ to $31^{\circ}$ (Fig. 4b). After 8 cycles, the cohesive force of each initial moisture content specimen reduced to $32.5 \mathrm{kPa}, 33 \mathrm{kPa}, 36 \mathrm{kPa}, 34.8 \mathrm{kPa}, 32.8 \mathrm{kPa}$, and $30.7 \mathrm{kPa}$, respectively. The maximum reduction value of $16.6 \mathrm{kPa}$ was at $13 \%$ initial moisture content specimen, and the minimum reduction value of $11.6 \mathrm{kPa}$ was at $43 \%$ initial moisture content specimen. As well as the internal friction angle, the maximum reduction value of $5.2^{\circ}$ was at $19 \%$ initial moisture content specimen, and the minimum reduction value of $3.3^{\circ}$ was at $25 \%$ initial moisture content specimen. Fig. 4a, b indicated that the vegetation cement-soil with $19 \%$ and $25 \%$ initial moisture content performed well.

Vegetation Cement-Soil Physical Properties: Due to the proportion of soil in vegetation cement-soil reaches $80 \%$, the evolution of vegetation cement-soil physical properties is closely related to the physical property of the yellow-brown earth we selected. It is known from Table 2 that the illite and montmorillonite in the yellow-brown earth account for $18 \%$, and the illite and montmorillonite will produce $30 \%$ to $40 \%$ and $50 \%$ to $60 \%$ unequal swelling during the wetting process, respectively (Ambroise et al. 1985, Jiang et al. 2013, Yang et al. 2010). As a result, the shrinkages of specimens were larger than the swelling no matter under laboratory conditions or during drying-wetting cycles (Figs. 1, 2). Unlike the expansive soil, which is dominated by the characteristic of swelling ranging from $13 \%$ to $6 \%$ after 4 drying-wetting cycles (Wang et al. 2015), the vegetation cement-soil is dominated by the physical properties of shrinkage ranging from $8 \%$ to $15 \%$ under different initial moisture content condition (Fig. 2). An appropriate proportion of cement in the vegetation cement-soil, which was obtained after many trials (Xu et al. 2012), plays a vital role to enhance its strength to avoid swelling.

Although the main characteristic of vegetation cement soil is shrinkage, the swelling could not be ignored during the wetting process. The hydrophilic substances of illite and montmorillonite would make the micro-cracks and pores emerged in the weak parts of cement soil (Walker et al. 1995), causing the weakening of the connectivity between particles. With the recurrence of the drying-wetting cycle, the micro cracks and pores acted as a path for water migration, and the particles and clay minerals were repeatedly eroded 

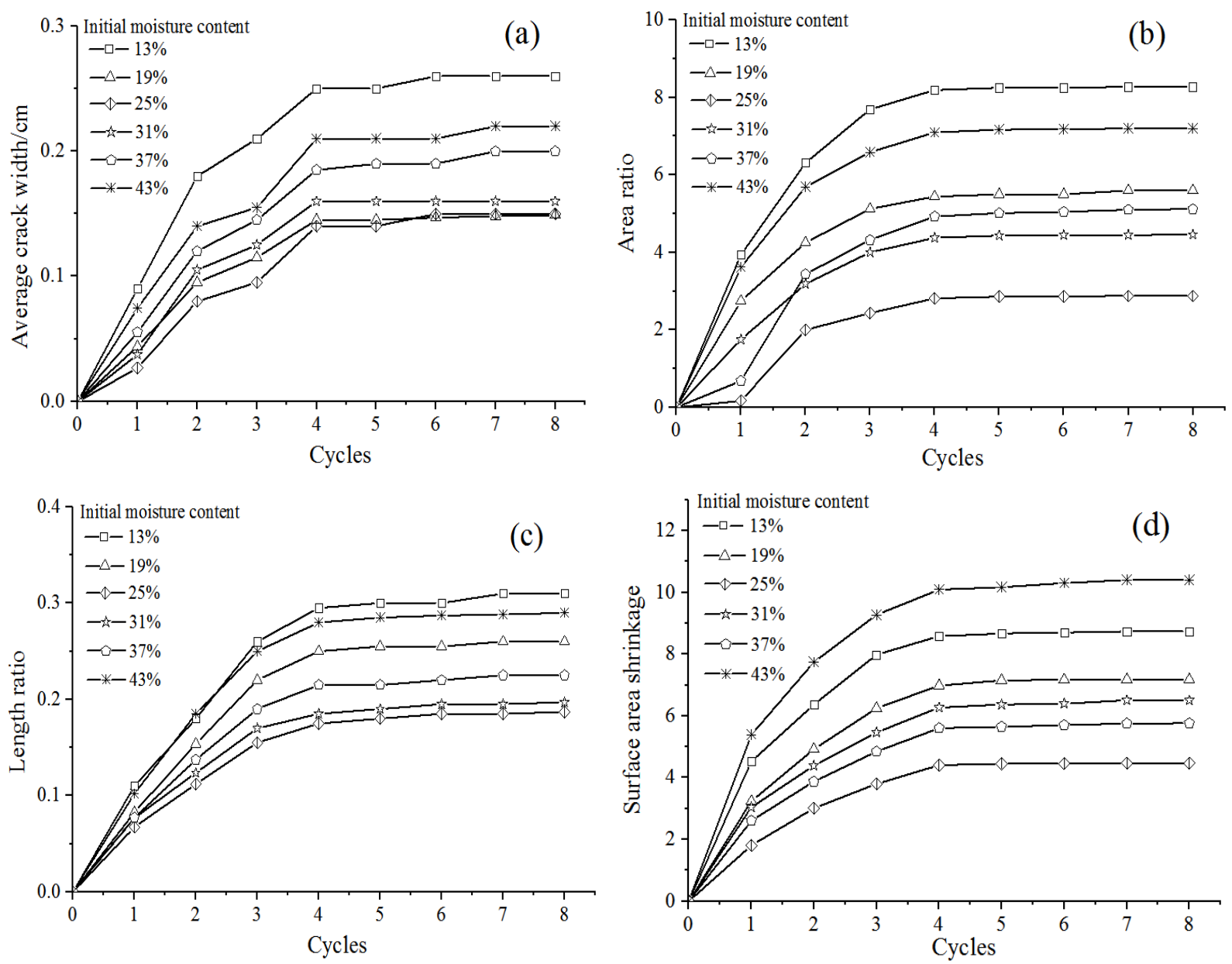

Fig. 3: Evolution of vegetation cement-soil under the drying and wetting cycles (a) Average crack width curve; (b) Area ratio curve; (c) Length ratio curve; (d) Surface area shrinkage curve.
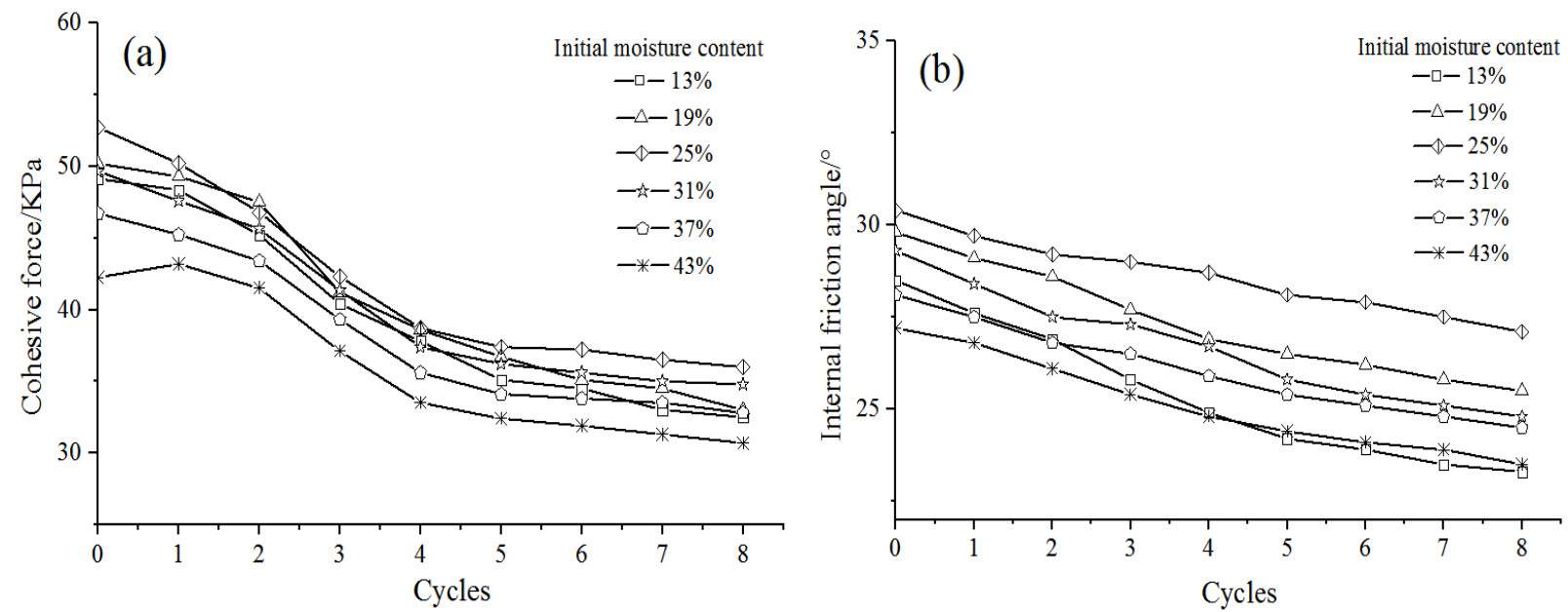

Fig. 4: Vegetation cement-soil mechanical-cycle curves (a) Cohesive force curve; (b) Internal friction angle curve. 
and dissolved by water (Kamei et al. 2013), resulting in the pores of vegetation cement-soil increased to destroy its structural and produce cracks eventually. Moreover, the main provider of strength, ettringite crystals, would pulverize and disintegrate after the carbonation reaction between cement and soil during the drying process, generating substances such as calcium carbonate, calcium sulfate, and large pores (et al. 2013), leading to the strength reduced. Pedreño-Rojas et al. (2019) found that the wood chips can cause microstructure damage and strength loss of composite materials after drying-wetting cycles. Liu et al. (2018) further proved that the organic material, such as sawdust, has a remarkable effect on the physical and mechanical properties of cement soil during drying-wetting cycles, and it could cause damage to cement-soil structures.

Vegetation Cement-Soil Mechanical Properties: For the yellow-brown earth, the influence of soil moisture content and dry bulk density on the shear strength has been explored by Wang et al. (2018). Results showed that the cohesion of yellow-brown earth, with different moisture content (25\%, $27 \%, 29 \%, 31 \%, 33 \%$ ), ranges from $10 \mathrm{kPa}$ to $40 \mathrm{kPa}$ under the dry bulk of $1.1 \mathrm{~g} . \mathrm{cm}^{-3}$, and the internal friction angle distributes from $25^{\circ}$ to $30^{\circ}$. Compared to the yellow-brown earth and concrete, the vegetation cement-soil has a medium shear strength. For the cohesion, the shear strength of vegetation cement-soil reduces with the increase of the cycles and the smallest cohesion is larger than $30 \mathrm{kPa}$, which has improved compared to the yellow-brown earth. Due to the small amount of cement mixed in the vegetation cement-soil, the internal friction angle is similar to yellow-brown earth. Despite the fact that vegetation has a lower shear strength than concrete, the purpose of developing vegetation cement-soil is to function as a specific substrate for restoring the cutting slope (Liu et al. 2018). As an artificial substrate, the vegetation cement-soil is not only widely applied in China (Liu et al. 2013), but also spread to Sudan (Mohammed et al. 2018). Hence, the shear strength improved significantly can ensure the stability of slope revegetation as well as the function of revegetation.

Effect of Initial Moisture Content: Unlike yellow-brown earth (Wang et al. 2016) or expansive soil, the vegetation cement-soil contains $6 \%$ organic matter. Liu et al. (2018) chose rice husks, sawdust, and corn distillers' and unhulled rice distillers' grain to research the effect of different organic matters on the vegetation cement-soil, and found that they have a remarkable effect on the substrates' porosity and mechanical properties due to the response of organic matter to water. Studies indicate that a higher porosity will reduce the strength of artificial materials like cement (Chen et al. 2013). However, organic matter can retain water to change the pore structure. Zheng et al. (2001) also pointed out that the weights of the organic matter which reached $5 \%$ among the solid material are suitable for plant growth, but $\mathrm{Xu}$ et al. (2012) insisted that plants can still grow effectively at the organic matter proportioning of $6 \%$ as well. Hence, we can alter the initial moisture content instead of organic matter and cement to control the function of vegetation cement-soil. It was found that the surface image of the specimen with $25 \%$ initial moisture content was the most complete by the comparison of different initial moisture content (Table 3). Based on the crack evolution (Table 3 ) and shear strength (Fig. 4), plant cement soil with a higher or lower initial moisture content would be more easily damaged by wetting swelling and drying shrinkage. In addition, the length and width of cracks were also affected by the initial moisture content, and the results were consistent with others studies (Tang et al. 2011). Compared to the cement and organic matter, the phenomenon in the paper of vegetation cement soil can be blamed on the initial moisture content during the drying and wetting cycles. Therefore, this paper focused on analyzing the impact of initial moisture content and providing an optimal initial moisture content of vegetation cement soil for enhancing the stability of the artificial substrate.

\section{CONCLUSION}

The following conclusions are drawn: (1) At laboratory temperature, the shrinkage of vegetation cement-soil presents three stages of cement hydration, shrinkage, and stabilization, and the shrinkage stage is the main characteristic of vegetation cement-soil during the drying-wetting cycles. (2) The specimens with different initial moisture content will produce cracks under the drying and wetting cycles, and the shrinkage cracks number, cracks length, cracks width, and cracks surface area are increased with the increase in the number of cycles and then tend to steady. But the cohesion and internal friction angle of the vegetation cement-soil are reduced. (3) The initial moisture content is the key factor affecting the vegetation cement-soil fissures. The specimen with initial moisture content from $25 \%$ to $31 \%$, which has optimal stability and is suitable for application in production practice.

\section{ACKNOWLEDGEMENTS}

This work has been supported by the Foundation for creating high-end talent-leading characteristic carriers of China (Grant No. B19-004-01), Key Laboratory of Mountain Hazards and Earth Surface Processes, Chinese Academy of Sciences (Grant No. KLMHESP-20-02), National Key R\&D Program of China (Grant No. 2017YFC0504902-02) and China Huadian Corporation Research Foundation (Grant No. 12IJD201800018). 


\section{REFERENCES}

Ambroise, J., Murat, M. and Péra, J. 1985. Hydration reaction and hardening of calcined clays and related minerals V. Extension of the research and general conclusions. Cem. Concr. Res., 15(2): 261-268.

Chu, W.J. 2015. The Characteristics and Rule of Deformation Crack Propagation Under the Wet and Dry Cycles Shrink: The Role of Red Clay Swelling. Master thesis, Guizhou University, Guizhou.

Chen, X.D., Wu, S.X. and Zhou, J.K. 2013. Influence of porosity on compressive and tensile strength of cement mortar. Constr. Build. Mater., 40: 869-874.

Diel, J., Vogel, H.J. and Schlüter, S. 2019. Impact of wetting and drying cycles on soil structure dynamics. Geoderma, 345: 63-71.

Jiang, Z.M., Ma, H.J., Tian, B.T. and Jiang S.P. 2013. Study on swelling property of tuff in Lancang Lead Ore by micro-analysis. Subgrade Eng., (2): 83-85, 88. (in Chinese)

Kamei, K., Ahmed, A. and Ugai, K. 2013. The durability of soft clay soil stabilized with recycled Bassanite and furnace cement mixtures. Soils Found., 53(1): 155-165.

Kong, L.W., Sayem, H.M. and Tian, H.H. 2018. Influence of dryingwetting cycles on soil-water characteristic curve of undisturbed granite residual soils and microstructure mechanism by nuclear magnetic resonance (NMR) spin-spin relaxation time (T2) relaxometry. Can. Geotech. J., 55(2): 208-216.

Kuwano, R., Suwal, L.P. and Beltran-Galvis, A.L. 2011. Change of physical and mechanical properties of sandy soil due to repeated water infiltration. Deform. Charac. Geomater., 46(11): 829-833.

Li, W., Liu, G.S. and Yao, T. 2014. Improvement of methods for crack image processing and crack feature extraction of expansive soil. Rock Soil Mech., 35(12): 3619-3626. (in Chinese)

Liu, D.X., Xu, W.N., Cheng, Z.L., Zhou, Z.J., Cai, X.Y. and Zhao, B.Q. 2013. Improvement test on frost resistance of vegetation-concrete and engineering application of test fruitage. Environ. Earth Sci., 69: $161-170$.

Liu, D.X., Zhao, B.H., Yang, Y.S., Xu, W.N., Ding, Y. and Xia, Z.Y. 2018. Effect of organic material type and proportion on the physical and mechanical properties of vegetation-concrete. Adv. Mater. Sci. Eng., (6): 1-8.

Mohammed, A., Xu, W.N. and Xia, Z.Y. 2018. Ecological and bioengineering studies for stabilizing the Wad Medani-Sennar roadside slope linking the Gezira and Sennar States. Adv. Civil Eng., (1): 1-11.

Pedreño-Rojas M.A., Morales-Conde M.J., Rubio-de-Hita P. and PérezGálvez F. 2019. Impact of wetting-drying cycles on the mechanical properties and microstructure of wood waste-gypsum composites. Materials, 12(11): 1829.

Rao, S.M. and Revanasiddappa, K. 2006. Influence of cyclic wetting drying on collapse behavior of compacted residual soil. Geotech. Geol. Eng., 24: 725-734.
Suddeepong, A., Intra, A., Horpibulsuk, S., Suksiripattanapong, C., Arulrajah, A. and Shen, J.S. 2018. Durability against wetting-drying cycles for cement-stabilized reclaimed asphalt pavement blended with crushed rock. Soils Found., 58(2): 333-343.

Tang, C.S., Cui, Y.J., Shi, B., Tang, A.M. and Liu, C. 2011. Desiccation and cracking behavior of clay layer from the slurry state under wettingdrying cycles. Geoderma, 166: 111-118.

Walker, P.J. 1995. Strength, durability, and shrinkage characteristics of cement stabilized soil blocks. Cem. Concr. Compos., 17(4): 301-310.

Wang, B.T., Zhang, C.H., Qiu, X.L, Ji, E.Y. and Zhang, W.H. 2015. Research on wetting-drying cycles' effect on the physical and mechanical properties of expansive soil improved by OTAC-KCl. Adv. Mater. Sci. Eng., 3(2): 1-7.

Wang, D.Y., Tang, C.S., Cui, Y.J., Shi, B. and Li, J. 2016. Effects of wetting-drying cycles on soil strength profile of silty clay in micropenetrometer tests. Eng. Geol., 206: 60-70.

Wang, N., Zhao, Y.P., Guo, X.P., Zhang, J.C. and Liu, S.L. 2018. Effects of soil moisture content and dry bulk density of different vegetation types on slope soil shear strength. J. Soil Water. Conserv., 38(6): 88102. (in Chinese)

Xiang, W. and Dong, X.J. 2012. Study of swelling characteristic of the weak expansive soil in Luwangfen for South-to-North water diversion project. Rock Soil Mech., 33(4): 986-992. (in Chinese)

Xu, W.N., Xia, Z.Y., Zhou, M.T., Liu, D.X. and Xia, D. 2012. The Vegetation Concrete Eco-Restoration Technology Theory and Practice. China Water \& Power Press, Beijing. (In Chinese)

Yang, K., Li, Z. 2010. Research on montmorillonite hydration expansion mechanisms. J. Chin. Ceram. Soc., 29(5): 1154-1158. (in Chinese)

Ye, H., Chu, C.F., Xu, L., Guo, K.L. and Li, D. 2018. Experimental studies on drying-wetting cycle characteristics of expansive soils improved by industrial wastes. Hindawi, 2018: 1-9.

Zhang, J. 2018. Experimental study on compressive strength and wet-dry cycle durability of polypropylene fiber cement soil, J. China Foreign Highway, 38(6): 235-238. (in Chinese)

Zhang, J., Gao, Y. and Luosun, Y.M. 2014. Shrinkage stress in concrete under dry-wet cycles: An example with a concrete column. Mech. Time-Depend. Mater., 18(1): 229-252.

Zhao, B.Q., Xia, L., Xia, D., Liu, D.X., Xia, Z.Y., Xu, W.N. and Zhao, J. 2018. Effect of cement content in vegetation concrete on soil physicochemical properties, enzyme activities, and microbial biomass. Nat. Environ. Pollut. Technol., 17(4): 1065-1075.

Zheng, B.F., Zhang, J.Y. and Li, S.C. 2001. Study on basic features of thick layer base material. Subgrade Eng., 3: 1-4. (in Chinese)

Zhou, X.L., Liu, C.W., Feng, B., Guo, B.B., Lu, Y.H. and Zhang, L.W. 2019. Effects of dry-wet circulation on cement-based composite filling materials. Chinese J. of Eng., 41(12): 1609-1617. (in Chinese)

Zhou, J., Xu, H.Z. and Hu, W.J. 2013. Impact of wetting-drying cycle effects on the stability of expansive soil slopes, Chinese J. Geotech. Eng., 35(zk2): 152-156. (in Chinese) 